\title{
Sociološki aspekti proučavanja i revitalizacije graditeljskog nasleđa
}

\section{Ana Pajvančić - Cizelj}

Univerzitet u Novom Sadu, Filozofski fakultet, Odsek za sociologiju, Srbija e-mail: pajvana@gmail.com

\section{Katarina Maksimov}

Zavod za zaštitu spomenika kulture grada Novog sada, Novi Sad, Srbija e-mail: katarinamaksimov@gmail.com

\begin{abstract}
SAŽETAK U radu se ističe značaj sociološke perspektive u proučavanju graditeljskog nasleđa i mogućnosti koje proizilaze iz uključivanja ove teme u sociologiju. Izdvajamo tri ključna istraživačka problema vrijedna sociološke analize 1) društvenu proizvodnju graditeljskog nasleđa, 2) društvene funkcije nasleđa i 3) odnos između različitih aktera unutar politika njegove zaštite i revitalizacije. Navedeni problemi situiraju se u širi teorijski okvir na tragu ideja Henrija Lefebvrea (1990.) i Michela Bassanda (2001.) te potkrepljuju odabranim rezultatima sociološke studije provedene u funkciji zaštite Petrovaradinske tvrđave u Novom Sadu. Zaključeno je da se nasleđe Petrovaradinske tvrđave proizvodi, reproducira i transformira kroz prakse niza različitih aktera ali one nisu prepoznate u procesima planiranja. Ne postoji jasna strategija upravljanja tvrđavom a njeni potencijali trenutačno nisu iskorišteni. Ukazano je na tenzije između svakodnevne, upotrebne vrednosti tvrđave i novih, gospodarskih funkcija utemeljenih na potrošnji. Ovi procesi sagledani su u kontekstu transformacije Novog Sada kao poluperiferijskog grada koja se odvija i preko transformacije njegova prostora uključujući i prostore graditeljskog nasleđa.
\end{abstract}

Ključne riječi: graditeljsko nasleđe, sociološki aspekti, akteri, Petrovaradinska tvrđava. 


\section{Uvod}

U dobu globalizacije simboličke i materijalne kulture, zaštita kulturnog nasleđa postaje sve atraktivnije polje proučavanja i delovanja. Zaštita kulturnog nasleđa, odnosno „dobara koje smo nasledili iz prošlosti a želimo preneti budućim generacijama zbog njihovog društvenog značaja i načina na koji utelovljuju identitet i osećaj pripadnosti“ (UNESCO, 2014.) mogla bi biti važan element očuvanja kulturnog identiteta zajednica u globalizovanom svetu. Nasleđe, sa druge strane, može predstavljati izvor sukoba oko njegovih nosilaca, interpretacija i funkcija. Ono, sve češće, postaje i sredstvo ekonomskog razvoja i međunarodne promocije pa dolazi do tenzija između identitetske funkcije u odnosu na lokalnu zajednicu i razvojne funkcije u odnosu na širi globalni okvir. Zaštita nasleđa i sama postaje medijator kulturne homogenizacije, usled sve veće standardizacije politika zaštite na globalnom nivou. Snažan naglasak na uključivanju različitih aktera i lokalne zajednice u ovim politikama ${ }^{1}$, pak, može proizvesti specifičan spoj globalnog i lokalnog odnosno voditi kulturnoj hibridizaciji nasleđa.

Graditeljsko nasleđe, kojim se bavimo u radu, je vrsta kulturnog nasleđa koje je materijalno i opipljivo (tangible) a uključuje građevine, istorijske lokalitete, spomenike i artefakte materijalne kulture (UNESCO, 2014.). U svetu „tekuće modernosti“ (Bauman, 2011.) graditeljsko nasleđe moglo bi se posmatrati kao nosilac struktura i barijera odnosno postojanosti kultura u prostoru i vremenu. Kao takvo, ono može predstavljati "živi" dokaz naše istorije, kulture i načina života i važnu sponu istorijskog kontinuiteta u zajednici. Transformacija graditeljskog nasleđa kroz diskurse i prakse zaštite, pak, može ukazati na razgradnju te postojanosti i destabilizaciju i fragmentaciju kulturnih značenja u savremenim uslovima.

U savremenim pristupima graditeljsko nasleđe se shvata kao resurs održivog razvoja (Barthel-Bouchier, 2013.) te dovodi u direktnu vezu sa društvenom zajednicom u kojoj postoji. Ukoliko održivi razvoj definišemo kao razvoj koji ne podriva temelje na kojima počiva, možemo reći da su ti temelji definisani i kulturom jedne zajednice koja je upisana u njeno graditeljsko nasleđe. U studiji Veća Europe, nedovoljno prepoznavanje vrednosti i značaja od strane lokalne zajednice identifikovano je kao jedan od važnih problema zaštite graditeljskog nasleđa u jugoistočnoj Evropi (Pickard, 2008.). Kada sami građani, stručnjaci i vlasti, ne pridaju odgovarajuće vrednosti i značaj graditeljskom nasleđu, ono lako gubi svoje društvene funkcije. Opšti društveni trendovi, poput ekonomske krize i neoliberalizacije urbane politike, dovode do smanjenja budžetskih izdataka za zaštitu graditeljskog nasleđa kao i do slabljenja lokalnih institucija planiranja i zaštite.Tako se graditeljsko nasleđe nalazi pred izazovima sa dve strane: iznutra, od strane samih lokalnih aktera i spolja od strane opštih društvenih procesa i trendova. Obe „strane“ problema su društvenog, sociološkog karaktera. U istraživanjima i praktičnim politikama zaštite kulturnog nasleđa sociološki pristupi nisu dovoljno zastupljeni a sociologija, sa druge strane, još

1 Na primer UNESCO Konvencija (2005.); Deklaracija iz Toleda (2010.), Ljubljanski proces/ deklaracija (2003.) ili Nova urbana agenda UN HABITAT-a (2016.). 
uvek nije prepoznala mogućnosti koje proizilaze iz istraživanja graditeljskog nasleđa niti je izgradila adekvatne teorijske i metodološke okvire za to.

U radu ukazujemo na značaj integracije sociološke perspektive u proučavanje graditeljskog nasleđa, odnosno mogućnosti koje proizilaze iz uključivanja ove teme u sociologiju. Izdvajamo dva ključna istraživačka problema vredna sociološke analize 1) problem društvene proizvodnje graditeljskog nasleđa, 2) problem društvenih funkcija graditeljskog nasleđa ${ }^{2}$ i 3) problem odnosa između različitih aktera unutar politika njegove zaštite. Navedeni problemi situiraju se u širi teorijski okvir na tragu ideja Henrija Lefebvrea (1990.) i Michela Bassanda (2001.) te potkrijepljuju odabranim rezultatima sociološke studije sprovedene u funkciji zaštite Petrovaradinske tvrđave u Novom Sadu.

\section{Mogućnosti za integraciju socioloških teorija u proučavanje graditeljskog nasleđa}

Problemi koji proizilaze iz proučavanja i zaštite graditeljskog nasleđa mogu biti tehničke, društvene ili humanističke prirode pa se, više ili manje sinhronizovano, proučavaju u različitim naučnim disciplinama poput arhitekture, istorije umetnosti, arheologije, muzeologije, etnologije, antropologije i slično. Iako je nužnost interdiciplinarnog pristupa u ovoj oblasti evidentna, tradicionalne podele između nauka još uvek su prisutne. Kulturni geograf Yi-Fu Tuan prenosi razgovor između fizičara Nielsa Bohra i Wernera Heisenberga prilikom zajedničkog obilaska jednog zamka u Nemačkoj. Bohr je tom prilikom rekao Heisenbergu:

„Nije li čudno kako se ovaj dvorac promeni čim zamislimo da je Hamlet živeo ovde? Kao naučnici, mi verujemo da se zamak sastoji samo od kamenja i divimo se načinu na koji su ga arhitekti sastavili. Kamenje, zeleni krov sa patinom, drvena rezbarija u crkvi, čine cijeli dvorac. Činjenica da je Hamlet tu živio ne bi trebala promijeniti ništa od toga ali ga ipak, mijenja u potpunosti“ (Tuan, 1977.:4).

Ovaj primer dobro oslikava nerazumevanja koje se mogu javiti između istraživača koji problemima graditeljskog nasleđa pristupaju iz uglova različitih naučnih disciplina. Iako je jedinstvenost materijalne i simboličke kulture utisnute u objekte graditeljskog nasleđa nesumnjiva, naša saznanja i dalje su fragmentisana zbog ukorenjenog jaza između prirodnih (tehničkih) i društvenih (humanističkih) nauka i njihovih paradigmi.

Osnovna karakteristika sociološke perspektive je da nasleđe posmatra u širem društvenom kontekstu te da je opremljena da takve veze istraži uz pomoć naučne metodologije. To znači da se problemu graditeljskog nasleđa pristupa holistički,

2 Funkcije i potencijali graditeljskog nasleđa u odnosu društvo u celini odnosno njegovi pojedini delovi. 
kontekstualno i kritički. U sociološkoj literaturi postoji iznenađujuće malo odrednica koje se odnose na graditeljsko nasleđe a ovaj pojam se veoma retko može naći i u sociološkim rečnicima. Druge discipine, dobro afirmisane u ovoj oblasti, ponekad fragmentarno preuzimaju određene sociološke koncepte ili istraživačke tehnike što može dovesti do amaterizacije sociologije i parcijalnog sagledavanja socijalnih aspekata kulturnog nasleđa. Dva pristupa razvijena najpre unutar urbane sociologije, mogla bi biti od izuzetne vrednosti za sociološku problematizaciju graditeljskog nasleđa - teorija prostora (Lefebvre, 1990.) i klasifikacija urbanih aktera (Bassand, 2001.).

\subsection{Društvena proizvodnja graditeljskog nasleđa}

Shvatanje Henrija Lefebvrea prema kome je svaki prostor društveno proizveden i preoblikovan te se kroz njega vrši reprodukcija i transformacija društva (1990.) mogla bi da služi kao polazni okvir za integraciju graditeljskog nasleđa u sociologiju. To znači da se ono ne može posmatrati izolovano od šireg socijalnog konteksta koji se sastoji od svakodnevnog života građana, ekonomskog i političkog sistema, dominantnog sistema vrednosti i ideologija u različitim istorijskim okolnostima. Društvo nije eksterno graditeljskom nasleđu, ne predstavlja pasivnu pozadinu niti iz njega proizilazi, već je aktivni činilac njegove proizvodnje i prethodi mu. Nosioci ekonomske, političke i kulturne moći definišu koji deo istorijskog nasleđa je vredan očuvanja, zbog čega, kakvu poruku nasleđe nosi, koje funkcije vrši i kome se obraća.

Svako društvo proizvodi sopstveni prostor pa se graditeljsko nasleđe može posmatrati i kao sredstvo reprodukcije dominantnih vrednosti, ideologija i društvenih odnosa kao i sredstvo društvene kontrole. Lefevr pokazuje kako se društvena proizvodnja prostora formira u međusobnoj interakciji 1) percipiranog - fizičkog prostora koji proizilazi iz svakodnevne upotrebe 2) zamišljenog prostora - mentalni, „objektivan“ prostor, konceptualizovan od strane stručnjaka, arhitekata i planera i 3) Življenog prostora - društveni prostor koji u sebi sadrži alternativna i potencijalno subverzivna značenja (Lefebvre, 1990.). Na tom tragu, možemo posmatrati odnose između svakodnevnog korišćenja nasleđa od strane lokalnog stanovništva, planova stručnjaka i različitih ideja i vizija o njegovom razvoju i funkcijama. Autor, nadalje, tvrdi da se u planiranju prostora življeni prostor ne može redukovati na zamišljeni, već je, upravo obrnuto, nužno poći od življenog prostora koji nastanjuju „organska, živuća i misleća bića“ i obuhvatiti njegove alternativne, simboličke i fragmentarne percepcije (Lefebvre, 1990.:229). Sociološko shvatanje, unutar koga se graditeljsko nasleđe dovodi u vezu sa odnosima moći u društvu, moglo bi ostati dovoljno otvoreno za uočavanje i konceptualizaciju alternativnih formi nasleđa, čija su značenja formulirana od dole, van dominantnih struktura moći (Robertson, 2008.). Prema Lefebvreu, transformacija društva počiva na transformaciji njegovog prostora što znači da je prostor političan. Proizvodnju prostora zato treba posmatrati kao dinamičan i konfliktan proces unutar kog se pregovaraju značenja i funkcije u odnosu na različite društvene grupe. 
Aktere u procesu proizvodnje i transformacije graditeljskog nasleđa moguće je identifikovati uz pomoć klasifikacije urbanih aktera ${ }^{3}$ Michela Bassanda (Basan, 2001.). On ističe kako urbana stvarnost ne funkcioniše mehanički već kao konfliktna sredina u kojoj se susreću i sukobljavaju različiti akteri od kojih neki upravljaju, drugi se opiru i osporavaju. Akteri su grupe koje nejednako raspolažu resursima, brane svoje interese i vrednosti, održavaju odnose sa drugima i nude projekte društva i svakodnevnog života koje žele da realizuju (Basan, 2001.). Autor identifikuje četiri grupe aktera u urbanoj politici: stručnjake za prostor (arhitekte, urbaniste, inženjere); ekonomske aktere (različita preduzeća, vlasnike zemljišta, ekonomske organizacije); političke aktere (funkcionere, političke partije i pokreti) i stanovnike/korisnike tj. građane (diferencirane po kulturi, društvenim obeležjima i sl.) (Basan, 2001.:348).

Kombinujući ove ideje, mogla bi se sagledati celina procesa društvene proizvodnje prostora graditeljskog nasleđa, društvene reprodukcije i transformacije kroz ove prostore, iz perspektive društvenih aktera koji u tim procesima učestvuju i njihovih međusobnih odnosa. Zaštita graditeljskog nasleđa morala bi da obrati pažnju kako na same objekte, tako i na društvene prakse i ideje koje su ih proizvele, koje ih reprodukuju i koje učestvuju u njihovoj transformaciji „Da bi razumjeli proces u kome se materijali ispunjavaju značenjem, moramo da promatramo prakse" (Law, 2010.:174). Ove procese, prema Yi - Fu Tuanu, možemo razumeti kao transformacije prostora (kao apstraktnih lokaliteta za koje ljudi nisu vezani) u mesta (kao lokaliteta kreiranih ljudskim iskustvima i ispunjenih smislom) (Tuan, 1997.). Na tom tragu moglo bi se tvrditi da je graditeljsko nasleđe uvek proizvedeno i reprodukovano i kroz nematerijalno, nevidiljivo nasleđe oličeno u socijalnim interakcijama, vrednostima, načinu života i odgovarajućim kulturnim praksama. Graditeljsko nasleđe stoga treba razumjeti pre kao dinamičan proces nego kao statičan artefakt. Njegovo istraživanje može daleko nadići pitanje neposrednih praktičnih rešenja i pokrenuti dublja pitanja istorijske proizvodnje, reprodukcije i transformacije društva kroz prostor (Harvey, 2001.).

\subsection{Društvene funkcije graditeljskog nasleđa}

U sociološkoj perspektivi, ključno pitanje funkcionalnosti graditeljskog nasleđa je: funkcionalno u odnosu na koga/šta? Prema Lefebvreu, funkcija prostora sastoji se u reprodukciji društvenog (kapitalističkog) sistema pri čemu infrastruktura grada postaje sastavni dio procesa reprodukcije kapitala (Grbin, 2012.). Sa druge strane, odnos "intimizacije sa vlastitim gradom se gradi na nivou prostora i prostornih značenja koja se svakodnevno koriste" (Pušić, 1997.:304), što govori o funkcijama prostora u izgradnji identiteta. Simbolička predstava grada kao cjeline kao važan element identiteta obično izvire iz onih prostora koji imaju istorijsku dimenziju i predstavljaju „vezni faktor“ urbanog kontinuiteta i kolektivnog identiteta (Pušić, 1997.:304).

U odnosu na to, može se postaviti pitanje koja je primarna društvena funkcija graditeljskog nasleđa u savremenim okolnostima? Da li je ono roba, kao i svaka druga,

3 Šire o urbanim akterima u Hrvatskoj vidjeti Seferagić, 2007.; Svirčić -Gotovac i Zlatar, 2012. 
ili ispunjava i druge funkcije koje proizilaze iz svakodnevne, lokalne, upotrebe? Jesu li ove dve funkcije kompatibilne, da li ih je moguće uskladiti ili se međusobno isključuju? Da li stručne službe u oblasti planiranja i zaštite nasleđa funkcionišu kao puki posrednici ekonomskih interesa i "implementatori ideoloških pretpostavki kapitalizma u prostor" (Grbin, 2012.) ili uspevaju da realizuju sopstvene vizije i usklade ih sa interesima građana? U odnosu na koga je graditeljsko nasleđe funkcionalno, koja mu je svrha i šta ono (p)održava? Ko učestvuje u definisanju ovih pitanja?

U savremenim pristupima zaštiti kulturnog nasleđa država i njena stručna tela više ne drže monopol na interpretaciju nasleđa. Prepoznaje se društvena konstrukcija nasleđa što vodi njegovom otvaranju i demokratizaciji. John Pendlebury (2008.) navodi da se unutar nove faze, koju naziva "doba konsenzusa", nasleđe više ne posmatra kao statična zaostavština u koju su utisnute nepromenljive vrednosti, već kao društveno posredovan, dinamičan proces. Rastakanjem modernističke paradigme nasleđe je obogaćeno perspektivom „drugih“ (lokalno stanovništvo, osetljive grupe). Tako se otvara važno sociološko pitanje identifikovanja ovih novih "glasova", odnosno "nasleđa isključenih grupa" (Buciek i Juul, 2008.), kao i njihovog uključivanja u procese planiranja i zaštite.

Uprkos paradigmatskim pomacima, (post)moderne prakse planiranja nisu vodile omoćavanju marginaliziranih grupa već njihovom, još većem, izopštavanju iz razvojnih procesa. Pretvaranje nasleđa u robu ili brand uz zapostavljanje upotrebnih vrednosti i funkcija, postaje ključno obeležje savremene neoliberalne paradigme u kojoj učestvovanje građana u politici postaje stvar forme a sve manje sredstvo suštinske preraspodele moći. Jedan od osnovnih motiva koji se javljaju u ovoj fazi je insistiranje na iskoristljivosti nasleđa i njegovim ekonomskim funkcijama (Pendelbury, 2008.; Harvey, 2005.). Savremeni globalizacijski procesi problem komodifikacije nasleda učinili su znatno složenijim. Lash i Lury (2007.) opisuju tranziciju sa kulturne industrije koja je počivala na samim kulturnim dobrima i funkcionisala logikom identiteta na globalnu kulturnu industriju koja počiva na brendu i funkcioniše po logici različitosti. Različite lokalne kulturne politike danas sve više oblikuju u odnosu na „udaljena mesta i događaje“ (Gidens, 2005.) pa su sve manje povezane sa lokalnim kontekstom.

\subsection{Odnosi aktera u politici zaštite graditeljskog nasleđa} Zeman, 2010.), učešće građana u procesu izrade politika, planova i strategija postaje jedna od veoma značajnih tema. Važnost učestvovanja u upravljanju graditeljskim nasleđem bazira se na najmanje dve premise sociološke prirode: a) graditeljsko nasleđe predstavlja važan aspekt kvaliteta života u određenoj zajednici i činilac dobrobiti građana; b) ono počiva na sposobnosti lokalne zajednice da ga očuva i unapredi. Uprkos tome što je u savremenim praksama planiranja i zaštite značaj učestvovanja zajednice jasno prepoznat, nema dovoljno smernica o tome kako bi taj proces trebao da izgleda u praksi. Na tom tragu, moguće je postaviti pitanje na koji način se lokalna zajednica uključuje u planiranje i koliku moć zajednica dobija u tom procesu. Institucije u konsultativni proces mogu da uključe različite aktere, ali 
se na takav način često ne uspevaju obuhvatiti interesi zajednice u celini ${ }^{4}$. Sociološki pristup trebao bi da teži prikupljanju objektivnih podataka o potrebama različitih grupa u zajednici. Iako to ne garantuje ostvarenje svih identifikovanih interesa, na ovakav način se osigurava iskustvena evidencija za kreiranje politika na temelju podataka i dokaza (evidence based policy). Unutar sociološkog pristupa, proces formulisanja politika zaštite sagledava se kao dinamičan i konfliktan što se odražava kroz međusobne odnose moći između različitih aktera.

\section{Osvrt na istraživanje socioloških aspekta zaštite i revitalizacije Petrovaradinske tvrđave u Novom Sadu}

Petrovaradinska tvrđava u Novom Sadu se smatra najprostranijom i najbolje očuvanom artiljerijskom bastionom tvrđavom u ovom delu Evrope, zidanom po principima Vaubanove škole ${ }^{5}$. Gradnja tvrđave započeta je 18. listopada (oktobra) 1762. godine postavljanjem kamena temeljca od strane princa Kroja, predstavnika austrougarskog cara Leopolda I, a trajala je sve do 1780. godine. Početkom 19. veka smatrana je za najsavremenije naoružanu i teško osvojivu tvrđavu austrijske monarhije (Babić, 2014.). Do danas sačuvana jezgra sastoji se od Gornje tvrđave (Festung ili Oberfestung), Donje tvrđave (Stadt ili Wasserstadt) i Hornverka (Hornwer) površine preko 150ha, sa ukupnom širinom spoljne linije odbrane od 5.500m. Sa zaštićenom okolinom, ovo kulturno dobro prostorno obuhvata gotovo 360 ha $^{6}$.

Različita društvena uređenja tokom istorije na ovim prostorima odrazila su se na prostore tvrđave i okolnih naselja i upisala svoje vrednosti u njihovu arhitekturu. Do 1918. godine tvrđava i njena okolina funkcionišu kao austrijski garnizon. Podgrađe $^{7}$, naselje u podnožju tvrđave, 1748. godine postalo je vojna gradska opština a

4 Zakon o planiranju i izgradnji (poslednja izmena "Sl. glasnik RS", br. 145/2014.), u Člano-
vima 41 (Dostupnost planskih dokumenata), 45a (Rani javni uvid) i 50 (Javni uvid) predviđa
mogućnost učešća građana u procesu izrade planskih dokumenata, pa i onih koji se odnose
na graditeljsko nasleđe.U praksi, međutim, ovi procesi najčešće budu završeni bez aktivnog
učestovanja javnosti, a u njima zastupljene isključivo ustanove i preduzeća koja, po svojoj de-
latnosti, imaju obavezu davanja podataka i uslova za izradu određenog planskog dokumenta.
Posledica su, neminovno, činovnički izrađeni urbanistčki planovi, bez prethodno postignutog
šireg konsenzusa. Šire u: Petovar; Vujošević, 2008 .

5 Sébastien de Vauban (1633-1707) francuski vojskovođa, arhitekta i pisac čija je škola unapredila dotadašnji bastionski sistem gradnje omogućavajući promene dužine elemenata prema konfiguaciji terena ili prema strategijskom značaju određenog dela (Babić, Maksimov, 2016.).

6 Iz "Studije zaštite Petrovaradinske tvrđave", izrađene za potrebe utvrđivanja granica kulturnog dobra i mera zaštite, od strane Zavoda za zaštitu spomenika kulture Grada Novog Sada. Studija je rađena od 2009. do 2014. godine, a trenutno se proceduralno nalazi u Ministarstvu kulture Republike Srbije u daljem pravnom procesu. Studija je rađena na predlog nadležnog Ministarstva kulture, sa ciljem prekategorizacije Tvrđave u kulturno dobro od naconalnog (izuzetnog) značaja, ali ta procedura još uvek nije dovršena.

${ }^{7}$ Podgrađe (Unutrašnji grad, Suburbium) je sastavni deo Donje tvrđave koja je sazidana na najnižoj koti, na okuci Dunava, naslanjajući se na petrovaradinsku stenu. 
unutar njega podignute su štabske zgrade, kasarne, vojni paviljoni, stambene kuće, administrativna i verska zdanja i čitav niz objekata različitih zanatlijskih delatnosti. Nakon Drugog svetskog rata, socijalističke vlasti menjaju socijalnu strukturu Podgrađa - na mesto nekadašnjih viših klasa oficira dolaze pripadnici niže radničke klase kojima se dodeljuju "društveni stanovi" u ovom delu grada. Današnje Podgrađe je sačuvalo objekte vojnog, civilnog i sakralnog karaktera koji su nastajali fazno, tokom celokupnog razvoja tvrđave a sadašnja namena prostora je prvenstveno stanovanje (Babić, 2014.).

Slika 1.

Pogled na Petrovaradinsku tvrđavu sa novosadske strane

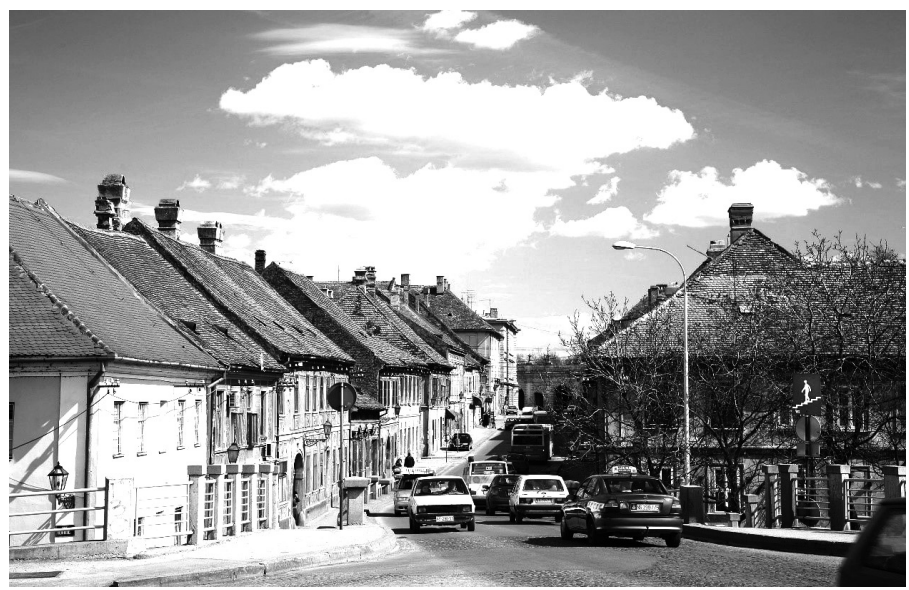

Izvor: Zavod za zaštitu spomenika kulture grada Novog Sada, http://www.zzskgns.rs/

Slika 2.

Pogled na Podgrađe, Beogradska ulica

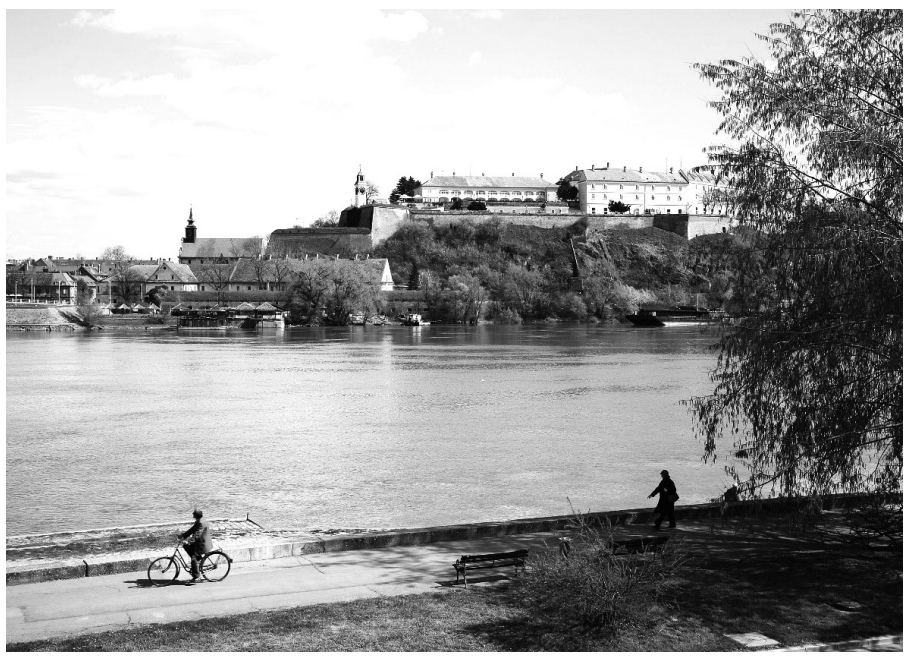

Izvor: Zavod za zaštitu spomenika kulture grada Novog Sada, http://www.zzskgns.rs/ 
Postepenom demilitarizacijom ${ }^{8}$ tvrđave otvaraju se mogućnosti za promenu osnovne, vojne namene a time i novi izazovi kao i potreba za integrativnom zaštitom. Petrovaradinska tvrđava stavljena je pod zaštitu države 1948. godine9 , za nepokretno kulturno dobro, prostorno kulturno-istorijsku celinu od velikog značaja utvrđena je $1991^{10}$. Uprkos tome što je doneto više strateških dokumenata koji se direktno ili indirektno odnose na zaštitu i revitalizaciju Petrovaradinske tvrđave ${ }^{11}$, ona se danas nalazi u izuzetno lošem stanju. To govori o nemoći aktera da je očuvaju i kvalitetno revitalizuju kao i o odsustvu jasne vizije o tome koji su potencijali ovog prostora i koje fukcije treba da ispunjava. Razvojni projekti grada koji utiču na zaštitu Petrovaradinske tvrđave (poput međunarodnog konkursa iz 2009. godine za izgradnju novog mosta preko Dunava, na stubovima nekadašnjeg Mosta cara Franca Jozefa ${ }^{12}$ ) često se kose sa mišljenjem konzervatora, ali i sa potrebama građana koji svoje nezadovoljstvo izražavaju protestima. Ovakav vid "dijaloga" dovodi do rasta tenzija između političkih aktera, građana i stručnjaka - konzervatora i otežava proces zajedničkog formulisanja rešenja. Kako je odgovornost za obnovu zaštićenih objekata sa stambenom namenom prebačena na građane (stanare), stanovnici Podgrađa nisu mogli da izdvajaju (vrlo visoka) sredstva za ovu namenu pa je čitavo naselje nastavilo da rapidno propada. Mnogobrojno vlasništvo na pojedinačnim parcelama se vidi kao uzrok otežanog održavanja i očuvanja od strane konzervatora (Babić, 2014.) ali i kao prepreka za razvojne projekte grada, što dodatno usložnjava međusobne odnose aktera.

8 Proces demilitarizacije do danas nije završen pa su određeni prostori i objekti i dalje u vlasništvu Vojske RS. Današnji kapaciteti vojske, prvenstveno u materijalnom smislu, nisu dovoljni za održavanje prostranog i kompleksnog kulturnog dobra, te je poslednjih desetak godina aktivirana prodaja objekata koji se ne koriste. Grad Novi Sad do sada nije pokazao interes da otkupi objekte koji se nude, za potrebe poboljšanja uslova korišćenja tvrđave i ojačavanje kulturnih i turističkih sadržaja.

9 Rešenjem br. 227 Zavoda za zaštitu i proučavanje spomenika kulture NR Srbije.

10 "Sl. list AP Vojvodine", br. 25, od 28. oktobra 1991. godine.

11 Teritoriju Petrovaradinske tvrđave tretiraju planski dokumenti na svim nivoima: od republičkog - Prostornog plana Republike Srbije od 2010. do 2020. godine, zajedno sa Zakonom o prostornom planu ("Sl. glasnik RS", br. 88/2010), preko Regionalnog prostornog plana AP Vojvodine ("Sl. lis APV", br. 22/11), do lokalnog Generalnog urbanističkog plana Novog Sada do 2021. ("Sl. list Grada NS", br. 39/06) ili Plana detaljne regulacije Petrovaradinske tvrđave ("Sl. list Grada NS", br. 61/10). Pored urbanističkih planova, postoji i određeni broj strateških dokumenata u kojima se ističe značaj očuvanja Tvrđave, potreba za njenom integrativnom zaštitom i očuvanjem za buduće generacije, poput Programa implementacije Regionalnog prostornog plana AP Vojvodine 2013-2017 gde je Petrovaradinska tvrđava definirana kao jedna od prioritetnih aktivnosti (http://195.222.96.93//rapp mape/RP/APVojvodine/Program\%20 implementacije\%20RPP\%20APV/Program\%20implementacije\%20RPP\%20APV.pdf, str. $17 \mathrm{i}$ 173), ili Srategija održivog razvoja Grada Novog Sada do 2020 (http://www.novisad.rs/sites/ default/files/documents/nacrt strategije odrzivog razvoja gns.pdf, str. 15). Nažalost, svi ovi dokumenti imaju velike nedostatke u procesima implementacije iz različitih razloga.

12 Most cara Franca Jozefa srušen je 11. travnja 1941. godine, a do danas su sačuvani stubovi koji vire iznad nivoa Dunava. 
Usled potrebe da se demistifikuje uloga različitih aktera u problemima vezanim za Petrovaradinsku tvrđavu, otvore pitanja njene zaštite i korišćenja, osigura učešce zajednice i pokrene princip preuzimanja odgovornosti, započet je rad na izradi Menadžment plana - plana upravljanja kulturnim dobrom ${ }^{13}$. Sociološko istraživanje za te potrebe, sprovedeno je 2015. godine i sastojalo se iz dva dela. U prvom, kvantitativnom delu, anketirani su građani Novog Sada na stratifikovanom ${ }^{14}$ slučajnom uzorku ( $n=503)$ koji se može smatrati reprezentativnim za grad Novi Sad. Drugi, kvalitativni deo, planiran je kao serija fokus grupnih razgovora i intervjua s političkim akterima (predstavnici odgovarajućih političkih institucija i nevladine organizacije koje deluju u oblasti zaštite Petrovaradinske tvrđave), ekonomskim akterima (vlasnici ugostiteljskih objekata i drugih ekonomskih delatnosti koje se sprovode na tvrđavi) i stručnjacima za prostor (predstavnici Zavoda za urbanizam, Zavoda za zaštitu spomenika kulture i različitih komunalnih preduzeća $)^{15}$. U radu prikazujemo odabrane rezultate koji se odnose na funkcije i potencijale Petrovaradinske tvrđave, njenu društvenu proizvodnju, reprodukciju i transformaciju kroz delovanje različitih aktera (sa posebnim naglaskom na učešće građana u ovim procesima) ${ }^{16}$.

\subsection{Funkcije i potencijali Petrovaradinske tvrđave}

Uprkos tome što je u istraživanju identifikovana značajna zainteresovanost građana za graditeljsko nasleđe u Novom Sadu ${ }^{17}$, oko 14\% ispitanika (i čak 30\% mladih između 15 i 25 godina) nije u stanju da navede ni jednu građevinu ili prostornu celinu koja spada u graditeljsko nasleđe. Preostalih $86 \%$ ispitanika kao graditeljsko nasleđe u Novom Sadu najčešće prepoznaju Petrovaradinsku tvrđavu (50\%), dok su ostali objekti u gradu poput starih građevina u centru prepoznati tek od malog broja ispitanika (oko 15\%). Čak 66\% ispitanika navodi da ima mnoga lična sećanja vezana za tvrđavu što govori o tome da ovaj prostor predstavlja i važan element ličnog identiteta građana. Ovakvi podaci govore nam da je Petrovaradinska tvrđa-

13 Menadžment plan se radi po metodologiji baziranoj na smernicama UNESCO, ICCROM i ICOMOS, u skladu sa savremenim principima zaštite kulturnog nasleđa i trebao bi da dovede do pomaka u pristupu upravljanju, očuvanju i korišćenju Petrovaradinske tvrđave.

14 Uzorak je stratifikovan teritorijalno (po delovima grada) i prema polu. Unutar svakog dela grada (ukupno 19 delova), ispitanici su u uzorak birani metodom slučajnog odabira („slučajni korak") uz stratifikaciju prema polu.

15 Iako je istraživanjem predviđeno da se ispitaju svi ključni akteri, do političkih i ekonomskih aktera nije bilo moguće u potpunosti doći. Taj podatak može da govori o njihovoj nezainteresiranosti za tvrđavu ali i moći koju poseduju. Sprega ekonomskih i političkih interesa u gradu omogućava im da realiziraju planove i „zaobiđu“ stručne zahteve u vezi prostora i interese građana.

16

6 Podaci su obrađivani uz pomoć deskriptivne statistike u programskom paketu SPSS.

17 Većina ispitanika (88\%) smatra da bi staro jezgro grada i objekte od kulturno - istorijskog značaja trebalo maksimalno zaštititi i očuvati ali i prilagoditi savremenim potrebama. 
va jedini jasno prepoznat lokalitet graditeljskog nasleđa u Novom Sadu i ključan simbol grada.

Realizacija identitetskih i simboličkih funkcija zavisi od toga koliko su građani informisani o tvrđavi, koliko je i na koji način koriste i kojim grupama je, i u kojoj meri, dostupna. Polovina ispitanika se o tvrđavi informisala samostalno, dok je tek oko $12 \%$ imalo prilike da o tome čuje nešto više od turističkih organizacija i stručnjaka. Na osnovu ovog i sličnih podataka, prepoznat je izostanak sisitemskog angažmana na širenju znanja o graditeljskom nasleđu i njegovih vrednosti po lokalnu zajednicu. Opšta je ocena svih ispitanika da tvrđava nije dovoljno iskorištena. U fizičkom pogledu, najveći deo tvrđave se ne koristi, dok postojeći kulturni i umetnički sadržaji, poput istorijskog arhiva i muzeja, imaju manje od 5\% redovnih posetlaca. Iako igra značajnu simboličku ulogu u ličnom i kolektivnom identitetu građana, društvene funkcije i potencijali Petrovaradinske Tvrđave nisu realizovane. Zaključeno je da opseg i kvalitet korišćenja prostora od strane građana predstavlja ključno pitanje njezinog budućeg razvoja ali ta pitanja nisu u fokusu razvojnih vizija ostalih aktera.

Kulturna dostupnost nasleđa bazira se na korištenju simbola i vrednosti različitih grupa koje žive na jednom prostoru. U ovom slučaju, posebno je značajno nasleđe hrvatske etničke zajednice koja tradicionalno nastanjuje Petrovaradin i Podgrađe ${ }^{18}$. Gotovo polovina ispitanika ne zna da odgovori na pitanje: Da li je, prema Vašem mišljenju, kultura različitih nacionalnih zajednica koje žive u Petrovaradinu dovoljno zastupljena $u$ interpretaciji $i$ promociji tvrđave $i$ Podgrađa, dok druga polovina smatra da nije. Ovaj problem najčešće prepoznaju upravo ispitanici koji pripadaju manjinskim etničkim grupama (Hrvati, Mađari, Nemci i oni koji se izjašnjavaju kao Jugosloveni).

Za stanovnike Podgrađa, Petrovaradinska tvrđava i njena zaštita duboko su isprepletani sa pitanjima svakodnevnog života. Tenzije između svakodnevne, upotrebne vrednosti ovog prostora, principa zaštite i vizija o njegovim ekonomskim funkcijama, očitavaju se u razlikama između potreba ispitanika iz Podgrađa i razvojnih vizija identifikovanih putem fokus grupnih razgovora. Stanovnici Podgrada su, u odnosu na ispitanike iz drugih delova grada, znatno manje zadovoljni kvalitetom života i niže ocenjuju gotovo sve elemente gradskog života (tabela 1.). Uprkos tome, $62 \%$ ispitanih ne želi da se preseli u drugi deo grada.

18 Jedan od značajnijih primera nasleđa hrvatske etničke zajednice u Podgrađu je rodna kuća Bana Josipa Jelačića, izuzetan primer barokne arhitekture na prostoru Vojvodine, sagrađena 1745. godine. Spomen ploča posvećena rođenju hrvatskog bana postavljena je početkom 20. veka na kojoj je zapisano: "U ovom domu rodio se 16. listopada 1801. slavni hrvatski ban grof Josip Jelačič". Usled velikih oštećenja koja su pretila da trajno oštete kuću, 2012. godine je grad Novi Sad u saradnji sa Hrvatskim nacionalnim vijećem detaljno sanirao krov i ulične fasade. 
Tabela 1.

Zadovoljstvo pojedinim aspektima života u svom delu grada (srednja ocena na skali od 1-5)

\begin{tabular}{|l|c|c|}
\hline & Podgrađe & Prosek za ostale delove grada \\
\hline Infrastruktura & 1,86 & 3,19 \\
\hline Socijalne usluge & 2,82 & 3,67 \\
\hline Snabdevenost (trgovina,tržnica) & 2,66 & 4,14 \\
\hline Kulturni sadržaji & 2,36 & 2,56 \\
\hline Socijalni život & 2,55 & 2,63 \\
\hline Sadržaji za decu (igrališta, igraonice) & 1,71 & 3,04 \\
\hline Sportski sadržaji & 1,52 & 2,92 \\
\hline
\end{tabular}

Predstavnici urbanističkog zavoda Podgrađe vide u odnosu na njegovu ekonomnsku odnosno turističku funkciju dok se privatno vlasništvo nad objektima vidi kao prepreka za razvojne projekte. Podgrađe bi, prema takvim vizijama, trebalo razvijati kroz zabavne sadržaje, ugostiteljstvo i turizam uz iseljavanje stanovnika i obnovu infrastrukture.

\subsection{Proizvodnja graditeljskog nasleđa Petrovaradinske tvrđave kroz delovanje aktera}

Istraživanjem je utvrđeno da se prostor tvrđave, "zamišljen” od strane stručnjaka ne podudara sa "življenim" prostorom unutar mentalnih predstava građana. Građani tvrđavu najčešće doživljavaju preko delova koje koriste a to su lokacije u neposrednoj okolini njenog gornjeg platoa, dok se konzervatori fokusiraju na znatno širi prostor tvrđave i njene okoline. Identikovan je i rascep između zvaničnog i nezvaničnog, lokalnog, znanja o tvrđavi. On se, između ostalog, ogleda i u tome što se tek 18\% ispitanika u potpunosti slaže sa stavom znam puno istorijskib činjenica o Turdavi a čak $40 \%$ potpuno se slaže sa stavom znam puno lokalnih priča i legendi o Turdavi. Utvrđeno je da su glavni nosioci priča i legendi o tvrđavi stanovnici Podgrađa koji u gotovo 75\% slučajeva navode da ih poznaju. Različite koncepcije nasleđa koje proizilaze iz "življenog” prostora zasigurno predstavljaju važan socijalni resurs za revitalizaciju Petrovaradinske tvrđave ali takve mogućnosti nisu prepoznate od strane stručnjaka. Ovakva značenja su nastala kao posledica položaja Podgrađa i njegove istorije a opstaju zahvaljujući društvenim odnosima i praksama koje u njemu postoje. Kao takva ona su fragilna i može se pretpostaviti da bi, u slučaju raseljavanja, bila izgubljena. Za razliku od istorijskih činjenica koje idu odozgo ka dole, ovakva vrsta nekodifikovanog znanja počiva na lokalnoj zajednici i prostoru. Ispitanim građanima posebno su intrigantna alternativna i neformalna znanja vezana za «neistražene» prostore, poput podzemnih katakombi. Prošlost o kojoj "svedoči" tvrđava može se, dakle, posmatrati dvojako: kao deo subjektivne memorije ili javne i zvanične istorije. Proizvodnja nasleđa odvija se na više nivoa ali to nije prepoznato jer gradske institucije koje deluju u ovoj oblasti uglavnom funkcionišu «iza zatvorenih vrata», unutar usko stručnog diskursa i često "po inerciji". 
Više od 75\% građana do sada nije ni na koji način učestvovalo u procesu planiranja Novog Sada a gotovo identičan postotak ne zna koja je institucija zadužena da vodi računa o tvrđavi, što govori o slabljenju kapaciteta i prepoznatljivosti lokalnih institucija planiranja i zaštite. To sasvim izvesno doprinosi krhkosti kolektivne predstave o ovom kulturnom dobru, odsustvu jasne i zajedničke vizije o njegovom značaju a time i do stanja u kome se tvrđava danas nalazi. Veliki broj ispitanika (87.5\%), smatra da bi građani trebali da imaju svoje predstavnike u institucijama koje upravljaju Petrovaradinskom tvrđavom, što trenutno nije slučaj. Stoga nije iznenađujuć ni podatak da tek oko 20\% ispitanika oseća da ima ulogu u očuvanju i unapređenju tvrđave ali bi gotovo polovina njih (nešto više od 45\%) bila spremna da se u to aktivnije uključi.

Česte smene lokalnih vlasti i izostanak dugoročnog planiranja dovode do toga da je upravljanje graditeljskim nasleđem diskuntinuirano i nestabilno a 73\% ispitanika smatra da su političari osnovni krivci za stanje u kom se tvrđava danas nalazi. Svi akteri ispitani fokus grupnim intervjuima (stručnjaci za prostor i nevladine organizacije koje deluju na promociji nasleđa tvrđave) prepoznali su nedostatak koordinacije i jasne upravljačke strukture kao najveći problem za razvoj i održavanje tvrđave. Trenutno ne postoji jedan organ nadležan za upravljanje tvrđavom i to ima praktične posledice u vidu neefikasnog rešavanja različitih problema. Nedostatak koordinacije ogleda se i u neefikasnoj komunikaciji različitih aktera, rascepkanim nadležnostima i sredstvima, neadekvatnom planiranju i praćenju realizacije različitih aktivnosti. Takođe, ne postoje jasni principi finansiranja aktivnosti vezanih za tvrđavu, ne prate se prihodi i rashodi koji se ostvaruju na prostoru tvrđave niti postoji mehanizam povratnog ulaganja u tvrđavu što otvara mogućnosti za različite vrste špekulacija.

\section{Zaključak}

Rečima Leonarda Benevola, materijalne strukture grada (njegove urbanističke i arhitektonske forme) čuvaju sećanje na istoriju grada a njihova izmena svedoči i o izmeni društva u celini (Benevolo, 2004.). Stoga izučavanje „fizičkog scenarija gradova“ i graditeljskog nasleđa može da doprinese razumevanju „komunikacije“ između prošlosti i sadašnjosti i načina na koji je budućnost uslovljena aktuelnim i istorijskim društvenim odnosima i odgovarajućim materijalnim strukturama.

Analizom procesa društvene proizvodnje Petrovaradinske tvrđave i njenog prostora kroz delovanje različitih aktera, moguće je steći uvid u procese društvene i istorijske transformacije Novog Sada. Istraživanjem je utvrđeno da tvrđava ima značajnu simboličku ulogu u formiranju i očuvanju ličnog i kolektivnog identiteta građana ali da je ona ugrožena usled slabog korišcenja, niskog nivoa informisanosti građana kao i nedovoljnog fokusa planera na lokalne potrebe. Identifikovane su i grupe čiji je odnos prema tvrđavi specifičan (posebno stanovnici Podgrađa). Ovi različiti "glasovi" nisu artikulisani niti jasno prepoznati unutar planova koje izrađuju stručnjaci pa se može reći da je moć građana kao aktera u zaštiti i revitalizaciji tvrđave na niskom nivou. Građani gotovo i ne znaju ko je zadužen da vodi računa o tvrđavi i slabo učestvuju u procesima planiranja grada. Stručnjaci angažovani na poslovima veza- 
nim uz Petrovaradinsku tvrđavu ne komuniciraju dovoljno sa građanima niti među sobom. Deluju bez jasne upravljačke strukture, sa podeljenim nadležnostima i nekoordinisano. Ne postoji kolektivna briga za tvrđavu niti jasna strategija njenog razvoja pa su funkcije koje ona vrši upitne i gotovo ih je nemoguće identifikovati. Vizije budućeg razvoja tvrđave iskazane od strane predstavnika institucija otkrivaju tenzije između svakodnevne, upotrebne vrednosti prostora u okolini tvrđave, potreba koje proizilaze iz njene zaštite i ekonomskih funkcija u odnosu na razvoj grada u celini.

Podaci do kojih smo došli mogu se razumeti u odnosu na polazne teorijske postavke i doprineti jačanju socioloških aspekata proučavanja graditeljskog nasleđa tek nakon adekvatne kontekstualizacije. Njih treba tumačiti u kontekstu opšte transformacije Srbije kao poluperiferijskog društva koja se realizuje (i) kroz transformaciju prostora. Politička transformacija iz autoritarnog u demokratsko društvo vodi diverzifikaciji aktera u oblasti zaštite graditeljskog nasleđa i izvesnom otvaranju procesa planiranja za različite grupe, vrednosti i interese. Ti akteri imaju priliku da dovedu u pitanje način na koji se (ne)upravlja prostorom i graditeljskim nasleđem i iniciraju promene. Kako su pokazala sociološka istraživanja, proces transformacije Srbije je diskontinuiran i "blokiran" (Lazić, 2011.) pa bi se moglo reći da je stanje u kojem se tvrđava danas nalazi prostorni otisak takvih opštih društvenih uslova. Akteri deluju u nekoj vrsti "vakuuma", u uslovima "kontekstualne neizvesnosti" i nepostojanja jasne strategije kao ključnih obeležja urbanog planiranja u postsocijalističkim društvima (Newman and Thornley, 2002.:24). Vizije planera razvoja počinju da se oslanjaju na ideju da će tržište rešiti sve probleme te se usmeravaju u pravcu neoliberalnih projekata restrukturiranja gradskih prostora. Unutar takvih vizija, revitalizacija graditeljskog nasleđa izjednačava se sa jačanjem njegovih ekonomskih funkcija. Društvene fukcije u odnosu na lokalno stanovništvo igraju sve manju ulogu što može voditi isključivanju i izmeštanju onih čiji su interesi drugačiji. Kako se trenutno najveći deo tvrđave zapravo ne koristi, niti se kroz nju realizuju neke značajnije ekonomske funkcije, može se očekivati da će socio-prostorna transformacija tek uslediti čime će i interesi aktera postati bolje artikulisani a konflikti između njih vidljiviji i intenzivniji. Trendovi koje smo uočili u istraživanju sugerišu da će se graditeljsko nasleđe verovatno transformisati u prostore proizvodnje i repodukcije kapitalizma, odnosno prostore potrošnje za nove globalne konzumente - turiste i više "kreativne" klase. Kako su ovi trendovi tek u povoju, mogu se očekivati i drugačiji scenariji, u odnosu na dinamiku i odnose moći među akterima, ali i stagnacija i izostanak razvoja u bilo 


\section{Literatura}

1. Babić, S. (2014). Petrovaradinska Tvrđava, U: Stančić, D. (Ur.). Umetnička topografija Novog Sada. Novi Sad: Matica srpska: 177-194.

2. Babić S. i Maksimov, K. (2016). Turđava Petrovaradin za 21. Vek: Uloga konzervatora u kreiranju scenarija razvoja. III Međunarodna konferencija "Očuvanje i unapređenje istorijskih gradova”, Sremski Karlovci (u pripremi).

3. Basan, M. (2001). Za obnovu urbane sociologije: jedanaest teza. Sociologija, 43 (4): 345-352.

4. Barthel - Bouchier, D. (2013). Cultural Heritage and Challenge of Sustainability. Walnut Creek: Left Coast Press.

5. Bauman, Z. (2011). Tekuća modernost. Zagreb: Naklada Palego.

6. Benevolo, L. (2004). Grad u istoriji Evrope. Beograd: Clio.

7. Buciek, K. and Juul, K. (2008). We Are Here, Yet, We Are Not Here: The Heritage of Excluded Groups, in: Graham, B. and Howard, P. (Eds.). The Ashgate Research Companion to Heritage and Identity. Hampshire: Ashgate, 105-125.

8. Geiger Zeman, M. i Zeman, Z. (2010). Uvod u sociologiju (održivih) zajednica. Zagreb: Institut društvenih znanosti Ivo Pilar.

9. Gidens, E. (2005). Odbegli svet: kako globalizacija preoblikuje naše živote. Beograd: Stubovi kulture.

10. Grbin, M. (2012). Lefevrova misao u savremenoj urbanoj sociologiji. Sociologija, Vol. LV, No.3: 475-491.

11. Harvey, D. (2001). Heritage pasts and heritage presents: Temporality, meaning and the scope of heritage studies. International Journal of Heritage Studies, Vol. 7, no 4: 319-338.

12. Harvey, D. (2005). Spaces of neoliberalization: towards a theory of uneven geographical development. Heidelberg: Franz Steiner Verlag.

13. John P. (2008). Conservation in the Age of Consensus. London: Routledge.

14. Lazić, M. (2011). Postsocijalistička transformacija i restratifikacija u Srbiji. Politička misao, 48/3: 123-144.

15. Lash, S. and Lury, C. (2007). Global cultural industry. Cambridge: Polity Press.

16. Law, J. (2010). The materials of STS, in: Hicks, D. and Beaudry, M. 8eds.). The Oxford Handbook of Material Culture Studies. Oxford: Oxford University Press: 173-191.

17. Lefebvre, H. (1990). The Production of Space. Oxford: Blackwell Publishing.

18. Newman, P and Thornley, A. (2002) Urban planning in Europe: International competition, national systems and planning projects. Taylor \& Francis e-Library.

19. Petovar, K. i Vujošević, M. (2008). Koncept javnog interesa i javnog dobra u urbanističkom i prostornom planiranju. Sociologija i prostor, 46/1: 23-51.

20. Pickard, R. (2008). Analysis and Reform of Cultural Heritage Policies in SouthEast Europe. Strasbourg: Council of Europe Publishing.

21. Robertson, I. (2008). Heritage from below: Class, social protest and Resistance, in: Graham, B. and Howard, P. (Eds.). The Ashgate Research Companion to Heritage and Identity. Hampshire: Ashgate, 143-159.

22. Seferagić, D. (2007). Akteri društvenih promjena u urbanom prostoru Hrvatske. Sociologija i prostor, 45 (3-4): 361-376.

23. Stančić, D. (2014). Umetnička topografija Novog Sada. Novi Sad: Matica srpska. 
24. Svirčić Gotovac, A. i Zlatar, J. (2012). Akteri društvenih promjena u prostoru; Transformacija prostora $i$ kvalitete života u Hrvatskoj. Zagreb: Institut za društvena istraživanja u Zagrebu.

25. Tuan, Y. (1977). Space and Place: The perspective of experience. London: University of Minnesota Press.

26. UNESCO (2014). Medium-term strategy 2014-2021. Paris. Pregledano 1.06.2016. (http://unesdoc.unesco.org/images/0022/002200/220031e.pdf).

\section{Popis slika:}

1. POGLED NA PODGRAĐE, BEOGRADSKA ULICA (Autorka fotografije Katarina Maksimov, dokumentacija Zavoda za zaštitu spomenika kulture Grada Novog Sada)

2. POGLED NA PETROVARADINSKU TVR円AVU SA NOVOSADSKE STRANE (Autorka fotografije Katarina Maksimov, dokumentacija Zavoda za zaštitu spomenika kulture Grada Novog Sada) 


\title{
Ana Pajvančić - Cizelj
}

University of Novi Sad, Faculty of Philosophy, Department of Sociology, Serbia

e-mail:pajvana@gmail.com

\section{Katarina Maksimov}

Institute for the Protection of Cultural Monuments of Novi Sad, Novi Sad, Serbia

e-mail: katarinamaksimov@gmail.com

\section{Sociological Aspects of Built Heritage Studies and Revitalisation}

\begin{abstract}
The paper highlights the sociological perspective in the study of built heritage and the possibilities arising from the inclusion of this topic in sociology. Three key sociological problems are identified: 1) social production of built heritage 2) social functions of the heritage and 3) relationships between different actors within the policies of its protection and revitalization. These problems are situated in a broader theoretical framework using the ideas of Henri Lefebvre (1990) and Michel Bassand (2001) and are illustrated by selected results of the sociological study conducted for the purposes of revitalization of the Petrovaradin Fortress in Novi Sad. The conclusion is that the Petrovaradin Fortress heritage is produced, reproduced and transformed in a variety of social practices which are not recognised in planning processes. There is no strategy for the management of the fortress and its functions and potentials are not fully realized. We recognize tensions between everyday, use value of the fortress and its surrounding area by the local population and new economic functions based on consumption. These processes are situated in the context of general transformation of the semi-peripheral town of Novi Sad and its space, including the spaces of built heritage.
\end{abstract}

Key words: built heritage, sociological aspects, actors, Petrovaradin Fortress. 